American J. of Engineering and Applied Sciences 2 (1): 236-240, 2009

ISSN 1941-7020

(C) 2009 Science Publications

\title{
Study of Porous Nanoflake ZnO for Dye-Sensitized Solar Cell Application
}

\author{
${ }^{1}$ H. Abdullah, ${ }^{1}$ N.P. Ariyanto, ${ }^{1}$ S. Shaari, ${ }^{3}$ B. Yuliarto and ${ }^{2}$ S. Junaidi \\ ${ }^{1}$ Department of Electrical, Electrics and Systems Engineering, Faculty of Engineering and Built \\ Environment, University Kebangsaan Malaysia, 43600 Bangi, Selangor, Malaysia \\ ${ }^{2}$ Department of Mechanical and Material Engineering, Faculty of Engineering and Built Environment, \\ University Kebangsaan Malaysia, 43600 Bangi, Selangor, Malaysia \\ ${ }^{3}$ Department of Physics Engineering, Institut Teknologi Bandung, Indonesia
}

\begin{abstract}
Problem statement: Nano-scale porous $\mathrm{ZnO}$ with high surface area have been studied to enhance physicochemical and electrochemical properties of certain optoelectronic devices applications. Approach: $\mathrm{ZnO}$ porous structure consists of flake-shape particles was synthesized through pyrolitic reaction of hydrozincite as Chemical Bath Deposition (CBD) product. Flake-like particle perpendicularly lied on substrate was obtained after 24 hours deposition. After calcinations, cavities on particle surface were observed as additional pores. Result: Sample crystallinity and morphology before and after calcinations were characterized by XRD, FTIR and SEM. Porosity profile was evaluated to its particle structure using $\mathrm{N}_{2}$ adsorption-desorption. Surface area was calculated using BET and it was $15 \mathrm{~m}^{2}$ gram $^{-1}$. Conclusion: The particle growth in CBD technique had been observed through its morphology and crystalline structure. Macropores structure was formed by cavities among the nanoflakes lied random on substrate and give surface area of $15.1866 \mathrm{~m}^{2} \mathrm{gram}^{-1}$.
\end{abstract}

Key words: hydrozincite, $\mathrm{ZnO}$, chemical bath depostition, porous, nanoflake

\section{INTRODUCTION}

Nano-scale porous $\mathrm{ZnO}$ with high surface area have been studied to enhance physicochemical and electrochemical properties of certain applications such as gas sensor ${ }^{[1]}$, photocatalyst ${ }^{[2]}$ and dye-sensitized solar cell photoelectrode ${ }^{[3]}$.

Manipulation of $\mathrm{ZnO}$ nanostructure to be various structures such as prismatic ${ }^{[4]}$, needle-like ${ }^{[5]}$, tetrapods ${ }^{[6,7]}$, nanorods ${ }^{[8,9]}$, nanobelts ${ }^{[10]}$, nanotubes ${ }^{[11]}$, nanocombs ${ }^{[12,13]}$ by various physical and chemical techniques attracts researchers to study their stillunknown properties. Among these various fabrication techniques, wet chemical route such as sol-gel, solvothermal, self-assembly, self-organization and chemical bath deposition, promises to be simpler, lessenergy demand, less expensive which is more profitable for large-scale production.

Direct deposition methods based on heterogeneous nucleation and subsequent crystal growth on substrate is the key of chemical bath deposition. Chemical bath deposition is used to deposit dense films of metal chalcogenides or metal oxides by single immersion of substrates in aqueous metal solutions ${ }^{[14]}$. Instead of fabricating dense $\mathrm{ZnO}$ films, we are tempted to fabricate porous $\mathrm{ZnO}$ films. The particle deposition of this method is based on heterogeneous nucleation on substrates in supersaturated solution relatively at low degree of super saturation. Control of solid kinetic formation in supersaturated solutions is obtained by adjusting the concentration, temperature, $\mathrm{pH}$ and selecting proper and adequate quantities of additives ${ }^{[15]}$.

This research is to focus on the microstructure and morphology properties of nanoflake $\mathrm{ZnO}$ thin films were prepared by Chemical Bath Deposition (CBD) technique to be applied for Dye-Sensitized Solar Cell.

\section{MATERIALS AND METHODS}

CBD solutions were synthesized by dissolving zinc nitrate hexahydrate (Analytical Reagent grade from Bendosen) and urea (purum $\geq 99 \%$ From Fluka) in DI water. This experiment used 0.05 and $1.0 \mathrm{M}$ of initial concentration of zinc nitrate and urea respectively. While stirring at room temperature, nitric acid was added to adjust the $\mathrm{pH}$ solution to 4 , formed clear solutions. Clean FTO substrates were put into the container as shown in Fig. 1. Nucleation was conducted by solutions heating in preheated oven at $70{ }^{\circ} \mathrm{C}$ for certain immersion time. As deposited films was

Corresponding author: H. Abdullah, Department of Electrical, Electrics and Systems Engineering, Faculty of Engineering and Built Environment, University Kebangsaan Malaysia, 43600 Bangi, Selangor, Malaysia 


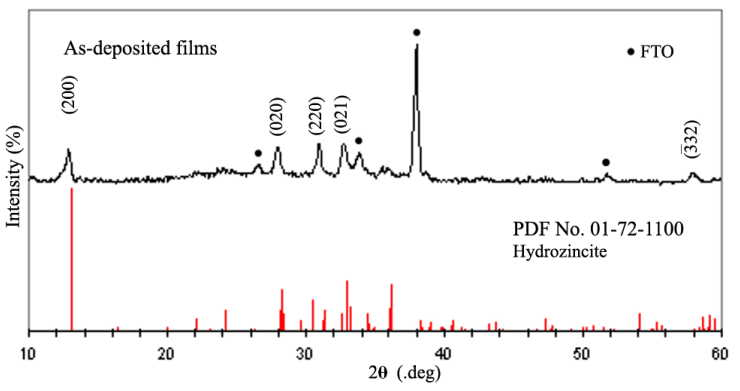

Fig. 1: Diffraction pattern of deposited film on FTO and reference pattern of hydrozincite

washed by DI water several times and dried at $50{ }^{\circ} \mathrm{C}$ for an hour in oven. Precipitated in bulk solutions was collected, washed several times with DI water and dried in oven at $50{ }^{\circ} \mathrm{C}$ for several days. The samples were calcined in air ambience at $300{ }^{\circ} \mathrm{C}$ for $30 \mathrm{~min}$ with $20^{\circ} \mathrm{C} / \mathrm{min}$ heat rate. Crystallinity of precipitated powder and film were characterized by Siemens D-5000 X-ray Diffractometer. IR spectra of each sample were obtained by Perkin Elmer Spectrum BX in spectral range between 4000 and $400 \mathrm{~cm}^{-1}$. Sample morphology was observed by Phillips XL30 Scanning Electron Microscope. Surface area measurement using BET calculation was measured by Micromeritic ASAP 2010.

\section{RESULTS AND DISCUSSION}

Figure 1 shows the diffraction pattern of deposited film on FTO, compared to reference of hydrozincite, PDF No 01-72-1100. It can be seen the deposited film has nearly similar peak intensity for peak corresponding to 200, 020, 220 and 021 plane. These dominant planes are believed as crystal growth orientation as films was being deposited on FTO substrate through heated bath solutions. The planes of (200), (020) and (220) indicate atoms are arranged in $c$-axis while (021) plane indicates atomic arrangement in $a$-axis. From this, we believed that our experimental condition would allow crystal growth in $c$-axis, which is perpendicular with substrate. Low intensities of diffraction peaks give information that deposited sample have little crystal structure.

Crystal structure analysis of calcined sample at 300 ${ }^{\circ} \mathrm{C}$ shows transformation from hyrozincite $\left(\mathrm{Zn}_{5}\left(\mathrm{CO}_{3}\right)_{2}(\mathrm{OH})_{6}\right)$ to zinc oxide $(\mathrm{ZnO})$ structure (as shown in Fig. 2). Referred to PDF No 00-36-1451, there are two dominant peaks represent (100) and (101) plane. By using Scherer equation, crystalline size of calcined sample is measured from (100) and (101) plane and results that the sample has $14.1 \mathrm{~nm}$ and 12.6 nm crystalline size, respectively.
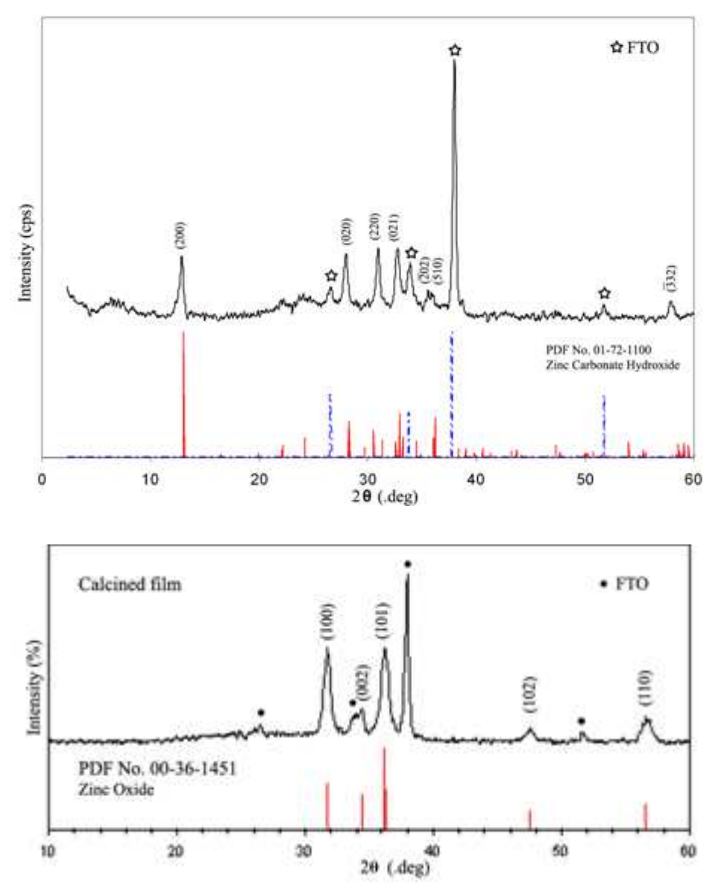

Fig. 2: Diffraction pattern of calcined sample and reference pattern of zinc oxide.

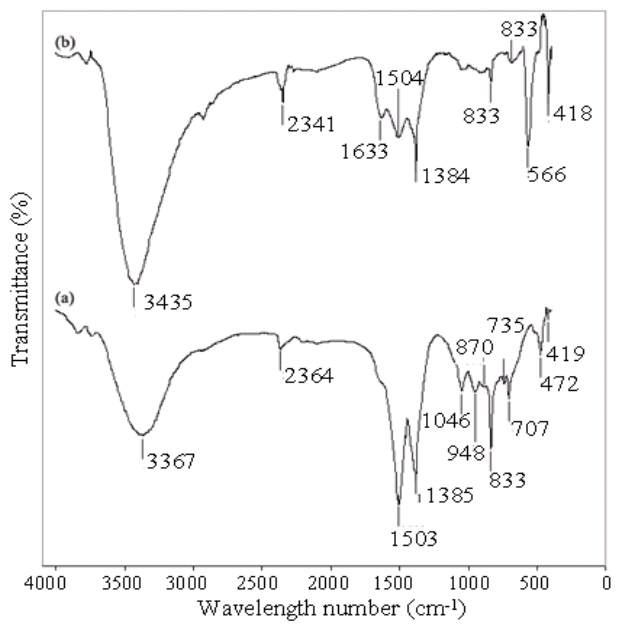

Fig. 3: IR spectra of (a) deposited film and (b) calcined film at $300{ }^{\circ} \mathrm{C}$

IR spectra of deposited film and calcined film are shown in Fig. 3. Band centered at $3367 \mathrm{~cm}^{-1}$ in deposited film IR spectra is the characteristic of $\mathrm{OH}$ stretching vibration of adsorbed water ${ }^{[16,17]}$ The carbonate bonding is attributed to absorption peak at 1503 and $1385 \mathrm{~cm}^{-1}$ for $\mathrm{v}_{3}$ asymmetric stretching mode of carbonate, and the bands centered at 1046 and 833 $\mathrm{cm}^{-1}$ are attributed to $\mathrm{v}_{1}$ stretching and $\mathrm{v}_{2}$ bending mode 


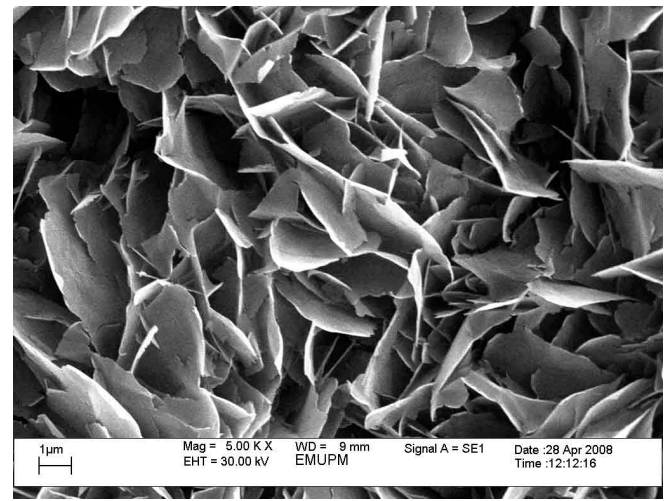

(a)

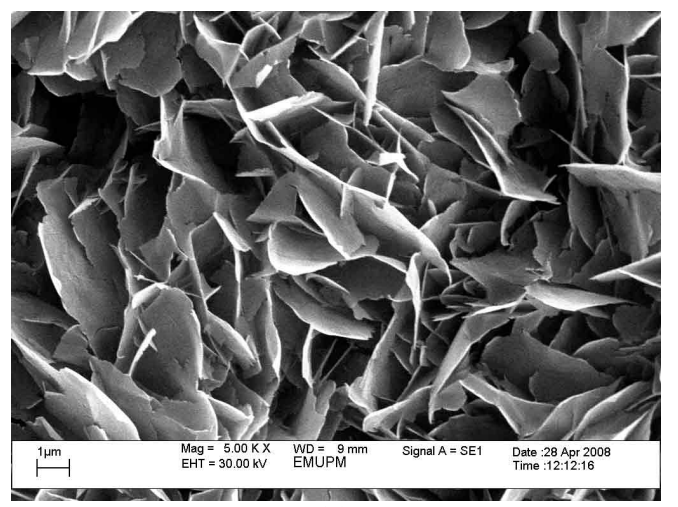

(c)

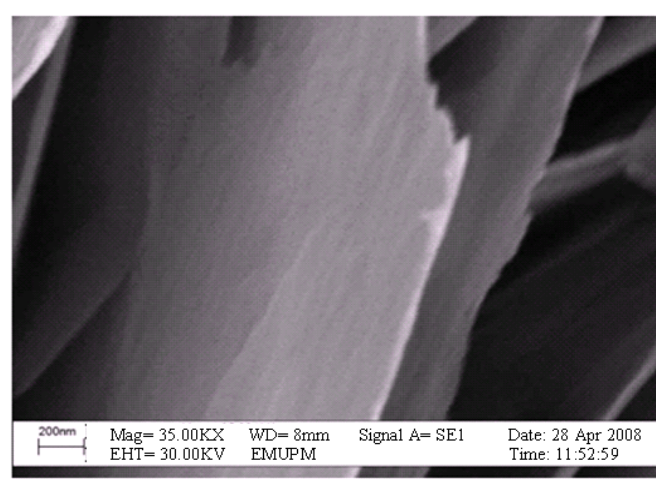

(b)

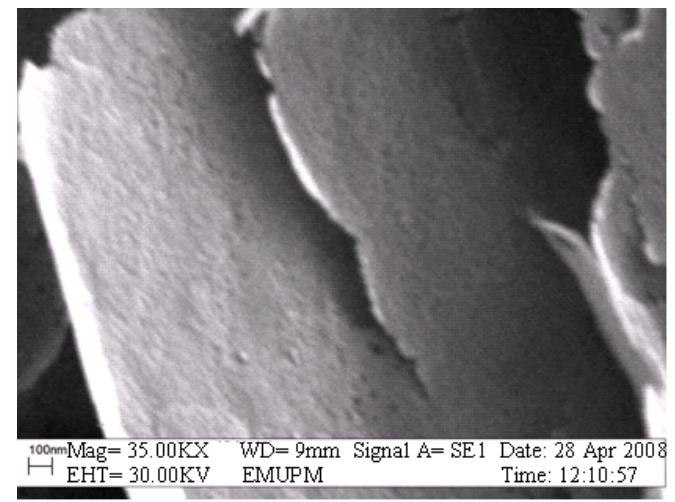

(d)

Fig. 4: SEM images of (a,b) as-deposited films and (c,d) calcined films after calcination at $300^{\circ} \mathrm{C}$ for $30 \mathrm{~min}$

of carbonate respectively, whereas the bands at 735 and $707 \mathrm{~cm}^{-1}$ attributed to $\mathrm{v}_{4}$ bending mode of carbonate ${ }^{[18,19]}$. These bands are assigned to hydrozincite carbonate bonding of hydrozincite ${ }^{[16-20]}$. It is also observed a band centered at $2364 \mathrm{~cm}^{-1}$ attributed to adsorbed $\mathrm{CO}_{2}$ in sample.

After calcinations at $300{ }^{\circ} \mathrm{C}$, the bands centered at 566 and $418 \mathrm{~cm}^{-1}$ in the IR spectra confirmed the presence of $\mathrm{ZnO}$. It is also noted IR spectra showing characteristic band of $\mathrm{ZnO}$ in fingerprint region can be used for confirmation of the shape of $\mathrm{ZnO}$ particles ${ }^{[19]}$. Spherical particle of $\mathrm{ZnO}$ has absorption peak at 485 $\mathrm{cm}^{-1}$ which well splits into two bands when the shape is changed. Prismatic microstructure will give bands at512 and $406 \mathrm{~cm}^{-1}$. In this study, the obtained band at 566 and $418 \mathrm{~cm}^{-1}$ are believed as confirmation of flakelike particle of $\mathrm{ZnO}$.

As-deposited films surface morphology observation shows that the films consist of nanosheets structure perpendicular to surface substrate. The nanosheets are separated by a micrometer scale of space as Fig. 4 showed Observation of surface morphology calcined films illustrated by SEM images shows there is no structural deformation occurred after calcination at $300{ }^{\circ} \mathrm{C}$ for $30 \mathrm{~min}$. The morphology is kept without any significant structural deformation. Low magnification images shows the flake structure with micrometer-scale spacing is kept after calcinations. Observation at higher magnification, at 35000 magnifications shows a rougher surface of nanosheet structure than asdeposited films. The observed cavities in particles are believed as effect of hydrozincite decomposition to transform into zinc oxide which formed nanopores.

Samples porosity profile is determined by $\mathrm{N}_{2}$ isotherm adsorption. The graph shows a Type II isotherm graph with slight rise in low partial pressure with small Type $\mathrm{H} 3$ adsorption hysteresis (as shown in Fig. 5). The isotherm adsorption graph relates sample microstructure which dominantly contains macropores represented by micrometer cavities between nanosheet particles. Despite, there is also predicted a mesopores structure in sample due to hysteresis existence at high partial pressure. The Type $\mathrm{H} 3$ adsorption hysteresis at high partial pressure was predicted as effect of platelike particle aggregation lead to slit-shaped pores on nanosheet particle surface ${ }^{[23]}$. Surface area calculation by BET gives a low value of $15.1866 \mathrm{~m}^{2} \mathrm{G}^{-1}$. 
Am. J. Engg. \& Applied Sci., 2 (1): 236-240, 2009

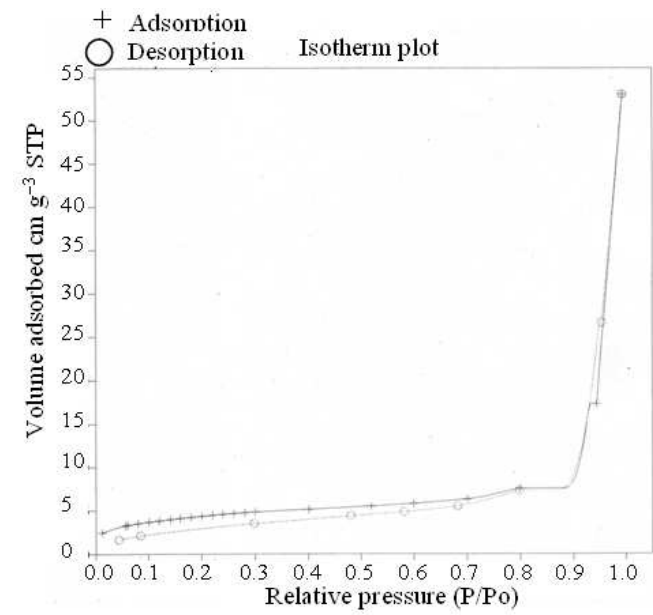

Fig. 5: Nitrogen adsorption-desorption plot

The low surface area is considered as films porous structure with dominantly consist of more macropores than mesopores. The mesopores structure is occurred due to carbonate and hydroxide decomposition in calcinations process.

\section{CONCLUSION}

The particle growth in CBD technique had been observed through its morphology and crystalline structure. Heterogeneous nucleation was considered at the beginning CBD process followed by particle growth based on 200, 020), (220) and (021) crystalline plane formed random nanoflake secondary particle. Calcination at $300^{\circ} \mathrm{C}$ successfully converted $\mathrm{Zn}_{5}\left(\mathrm{CO}_{3}\right)_{2}(\mathrm{OH})_{6}$ to $\mathrm{ZnO}$ structure without any deterioration of flake structure. Macropores structure was formed by cavities among the nanoflakes lied random on substrate and give surface area of 15.1866 $\mathrm{m}^{2}$ gram $^{-1}$.

\section{ACKNOWLEDGEMENT}

We thank to The Ministry of Science, Technology and Innovation of Malaysia which is gratefully acknowledged for the grant under Science Fund vote: 03-01-02-SF0386. The project was fully carried out in Photonics Laboratory, IMEN, UKM and partial characterization is undergone in Faculty of Science and Technology Laboratory. This study was also sponsored by UKM-OUP-NBT-26-117/2008 (Group of Nanomaterials Engineering) is grateful thanks.

\section{REFERENCES:}

1. Wagner, T., et al., 2007. Thin Solid Films. 515: 8360-8363.

2. Hariharan, C., 2006. Photocatalytic degradation of organic contaminants in water by $\mathrm{ZnO}$ nanoparticles: Revisite. Appl. Catalysis A: General, 304: 55-61. DOI: 10.1016/j.apcata.2006.02.020.

3. Keis, K., C. Bauer, G. Boschloo, A. Hagfeldt, K. Westermark, H. Rensmo and H. Siegbahn, 2002. Nanostructured $\mathrm{ZnO}$ electrodes for dyesensitized solar cell applications. J. Photochemistry Photobiology A: Chem., 148: 57-64. DOI: 10.1016/S1010-6030(02)00039-4.

4. Lin, C.C., K.H. Liu and S.Y. Chen, 2004. Growth and characterization of $\mathrm{Zn}-\mathrm{ZnO}$ core-shell polygon prismatic nanocrystals on Si. J. Crystal Growth, 269: 425-431. DOI: 10.1016/j.jcrysgro.2004.05.064.

5. McBride, R.A., J.M. Kelly and D.E. McCormack, 2003. Growth of well-defined $\mathrm{ZnO}$ microparticles by hydroxide ion hydrolysis of zinc salts. J. Mater. Chem., 13: 1196-1201. DOI: 10.1039/b211723c.

6. Newton, M.C. and P.A. Warburton, 2007. ZnO tetrapod nanocrystals. Mater. Today, 10: 50-54. DOI: 10.1016/S1369-7021(07)70079-2.

7. Newton, M.C., S. Firth, T. Matsumura and P.A. Warburton, 2006. Synthesis and characterization of zinc oxide tetrapod nanocrystals. J. Physics. Conference Series, 26: 251-255.

8. Hu, X.L., Y.J. Zhu and S.W. Wang, 2004. Sonochemical and microwave-assisted synthesis of linked single-crystalline $\mathrm{ZnO}$ rods. Mater. Chem. Phy., $\quad 88:$ 421-426. http://www.iop.org/EJ/article/17426596/26/1/060/jpconf6_26_060.pdf?request$\mathrm{id}=28 \mathrm{ff} 615 \mathrm{~b}-8 \mathrm{~b} 26-4 \mathrm{~d} 03-\mathrm{a} 05 \mathrm{~d}-595 \mathrm{a} 098 \mathrm{c} 7 \mathrm{a} 58$.

9. Zhou, W.D., X. Wu, Y.C. Zhang and M. Zhang, 2007. Solvothermal synthesis of hexagonal $\mathrm{ZnO}$ nanorods and their photoluminescence properties. Mater. Lett., 61: 2054-2057. DOI: 10.1016/j.matlet.2006.08.014

10. Zhang, J., W. Yu and L. Zhang, 2002. Fabrication of semiconducting $\mathrm{ZnO}$ nanobelts using halide source and their photoluminescence properties. Phy. Lett. A., 299: 276-281. http://cat.inist.fr $/$ ?aModele $=$ afficheN\&cpsidt $=1375$ 8495. 
11. Wang, R.M., Y.J. Xing, J. Xu and D.P. Yu, 2003. Fabrication and microstructure analysis on zinc oxide nanotubes. New J. Phy., 5: 115. http://www.iop.org/EJ/article/13672630/5/1/115/njp3_1_115.html.

12. Xu, C.X., X.W. Sun, Z.L. Dong and M.B. Yu, 2004. Self-oragnized nanocomb of $\mathrm{ZnO}$ fabricated by Au-catalyzed vapor-phase transport. J. Crystal Growth, 270: 498-504. http://cat.inist.fr/?aModele $=$ afficheN\&cpsidt $=1611$ 4514.

13. Lim, Y.S., J.W. Park, S.T. Hong and J. Kim, 2006. Carbothermal synthesis of $\mathrm{ZnO}$ nanocomb structure. Mater. Sci. Eng. B., 129: 100-103. DOI: 10.1016/j.mseb.2005.12.021.

14. Kakiuchi, K. E. Hosono, T. Kimura, H. Imai and S. Fujihara, 2006. Fabrication of mesoporous $\mathrm{ZnO}$ nanosheet from precursor template grown in aqueous solutions. J. Sol-Gel Sci. Tech., 39: 63-72. DOI: 10.1007/s10971-006-6321-6.

15. Govender, K., D.S. Boyle, P.B. Kenway and P. O'Brien, 2004. Understanding the factors that govern the deposition and morphology of thin films of $\mathrm{ZnO}$ from aqueous solutions. J. Mater. Chem., 14: 2575-2591. DOI: 10.1039/b404784b.

16. Li, Z., X. Shen, X. Feng, P. Wang and Z. Wu, 2005. Non-isothermal kinetics studies on the thermal decomposition of zinc hydroxide carbonate. Thermochimica Acta, 438: 102-106. http://cat.inist.fr/?aModele $=$ afficheN $\&$ cpsidt $=1729$ 9680 .
17. Wahab, R., S.G. Ansari, Y.S. Kim, M.A. Dar, H.S. Shin, 2008. Synthesis and characterization of hydrozincite and its conversion into zinc oxide nanoparticle. J. Alloys Compound, 461: 66-71. http://cat.inist.fr $/$ ?aModele $=$ afficheN\&cpsidt $=2048$ 7090.

18. Kanari, N., D. Mishra, I. Gaballah and B. Duppree, 2004. Thermal decomposition of zinc carbonate hydroxide. Thermochimica Acta, 410: 93-100. DOI:10.1016/S0040-6031(03)00396-4.

19. Hales M.C. and R.L. Frost, 2007. Synthesis and vibrational spectroscopic characterization of synthetic hydrozincite and smithsonite. Polyhedron, 26: 4955-4962.

20. Gadsten, J.A., 1975. Infrared Spectra of Minerals and Related Inorganic Compound. Butterworth, London, pp: 277. ISBN: 0-408-70665-1.

21. Bitenc, M., M. Marinsek and Z.C. Orel, 2008. Preparation of zinc hydroxide carbonate and porous zinc oxide particle. J. Eur. Ceramic Soc., 28: 2915-2921. DOI: 10.1016/j.jeurceramsoc.2008.05.003.

22. Sing, K.S.W., D.H. Everett, R.A.W. Haul, L. Moscou, R.A. Pierotti, J. Rouquerol and T. Siemieniewska, 1985. Reporting physisorption data for gas/solid systems with special reference to the determination of surface area and porosity. Pure Applied Chem., 57: 603-619. http://stage.iupac.org/originalWeb/publications/pac /1985/pdf/5704x0603.pdf. 